\title{
Quantifying Climate Change Impacts on Hydropower Generation and Implications on Electric Grid Greenhouse Gas Emissions and Operation
}

\author{
Brian Tarroja*a $^{* a}$ Amir AghaKouchak ${ }^{\mathrm{a}, \mathrm{b}}$, Scott Samuelsen ${ }^{\mathrm{a}, \mathrm{c}}$ \\ ${ }^{a}$ Advanced Power and Energy Program, University of California - Irvine \\ University of California Irvine, Engineering Laboratory Facility, Irvine, CA, USA, 92697-3550 \\ ${ }^{b}$ Department of Civil and Environmental Engineering, University of California - Irvine \\ University of California Irvine, Engineering Gateway Building, Suite E4130, Irvine, CA, USA, 92697-2175 \\ ${ }^{\mathrm{C} D e p a r t m e n t}$ of Mechanical and Aerospace Engineering, University of California - Irvine \\ University of California Irvine, Engineering Gateway Building, Suite E4230, Irvine, CA, USA, 92697-2175 \\ *Corresponding Author: Email: bjt@apep.uci.edu, Phone: (949) 824-7302 x 11-348
}

\section{Abstract}

Here we translate the impacts of climate change on hydropower generation, and discuss implications on greenhouse gas (GHG) emissions and operation in California. We integrate a model of major surface-water reservoirs with an electric grid dispatch model, and perturb it by projected runoff based on representative concentration pathways (RCP4.5 and RCP8.5). Results show that climate change and variability is expected to decrease the average annual hydropower generation by $3.1 \%$ under RCP4.5, but have negligible impact under the RCP8.5. Model simulations indicate more inflow, caused by more future extremes, in the future that does not necessarily translate to more energy production because of reservoir spillage of water. While overall volume of future available water for energy production may be similar or higher, the delivery of this volume is expected to be significantly more variable in the future climate than the historical average, which has many implications for hydropower generation. Our results show that the expected changes in future climate leads to increases in grid GHG emissions, load-following capacity, fuel usage, and costs for the RCP4.5 due to generation shortfall, and very slight increases in the same metrics for the RCP8.5 case due to variability causing decreased efficiencies in load-following power plants.

\section{Introduction}

Concerns over the impacts of climate change on the physical and economic environments have driven the development and deployment of a wide range of advanced technologies. Electrification has been determined to fulfill a key role in the decarbonization of many services [1] and therefore many of the advanced technologies have been centered of providing carbon free electricity. This has driven the deployment of renewable resources such as wind and solar power in many areas, with many states in the U.S. deploying renewable portfolio standards [2]. California in particular has very aggressive renewable portfolio standards, with a $50 \%$ goal by 2030 [3]. 
Managing the integration of renewable resources for carbon reduction on the electric grid requires the use of dispatchable generation. In many regions, hydropower fulfills a significant portion of this role on the electric grid. Hydropower generation is ideal for providing dispatchable generation due to a number of characteristics over other resources which can provide these services such as natural gas combined cycle plants. These include but are not limited to:

- No need for fuel input in the conventional sense to provide generation, compared to fossil fuel input requirements for dispatchable thermal power plants.

- No efficiency penalties or emissions increases when operating at part load or during ramping and start up events.

- Ability to ramp and start up over very short timescales

- No greenhouse gas emissions in operation while performing grid services.

Climate change and variability, however, is expected to impact precipitation and runoff in many regions which serve as the inflows to surface reservoirs at hydropower plants. These impacts include but are not limited to changing the timing of runoff and the overall magnitude of precipitation and runoff which affects the overall potential contribution of hydropower to the electric generation portfolio. These impacts can jeopardize the ability of hydropower to perform load-balancing services for the electric grid. To compensate for the shortfall in these services, other resources may need to operate and be dispatched to keep the electric load balanced, especially with more renewable resources on the grid. These other resources may not have the same advantages as hydropower, especially with respect to greenhouse gas emissions.

Depending on the severity of these impacts, they need to be taken into account for the planning of strategies for emissions reduction. This study seeks to provide an example of one method for accounting for hydropower generation under future climate simulations, and the corresponding impacts on emissions and grid design. This has been achieved by combining a water reservoir network model with a detailed grid resource dispatch model, forced with inflows simulated from climate model projections.

\section{Background}

The effects of climate change and variability on precipitation, temperature and runoff have been studied extensively in the literature over the last decade [4-6]. In the western United States, the observed increase in droughts and heatwaves [7], shifts in runoff timing [8] and substantial increase in anthropogenic water demand [9] have raised concerns on climate impacts on energy production. Many studies have examined how climate change for a given region impacts surface runoff and hydropower generation [10]. The primary gap in the literature is a translation of these effects to grid operation and emissions impacts by coupling these results with the constraints of the electricity system. This study aims to address this important research gap. Current studies in the literature which have examined hydropower in the context of climate change are described as follows. 
Hamlet [11] performed a study which examined the projected effects of climate change on energy supply and demand in the Pacific Northwest region of the U.S, a large component of which is hydropower. This study incorporated climate scenarios for 2010-2039, 2030-2059, and 2070-2099 to examine changes in annual and seasonal hydropower generation, as well as changes in electricity demand due to cooling loads and used the ColSim model to simulate hydropower reservoir operations in 20 reservoirs in the state. This study found that annual hydropower production in the Colombia River Basin was reduced by $2.0-3.4 \%$ by 2040 , and $2.6-3.2 \%$ by 2080 with the largest reductions occurring in the summer during the times of peak air conditioning loads.

Kao [12] examined the impact of climate change on 132 federal hydropower plants in the U.S. for 18 different study areas across the country ranging from the pacific northwest to the southeast. This study used the United States Geographical Survey (USGS) WaterWatch runoff to provide observational runoff data, and used a combination of global climate models, regional climate models, and hydrologic models for each region along with climate scenarios from the Intergovernmental Panel on Climate Change Assessment Report 4 (IPCC AR4) reports. This study, however, did not take into account the constraints of reservoir operation and made projections primarily based on runoff volume. It was found that in the Pacific Northwest regions, average annual hydropower generation increases by $1.7 \%$ over 2010-2024 and by 3.3\% over 2025-2039, but did not account for operational issues at the reservoir level. Hydropower in the Western Power Administration, Southwest Power Administration, and Southeastern Power Administration regions were also projected to increase overall, but with high variability.

Madani [10] investigated the impact of climate change on high elevation hydropower in California for 137 high elevation hydropower plants using an Energy-Based Hydropower Optimization Model (EBHOM) and dry, wet, and temperature warming only climate scenarios. The EBHOM methodology optimizes hydropower generation revenue based on on-peak and off-peak pricing within the constraints of reservoir capacity. This study predicted a reduction of $19.7 \%$ in hydropower generation for the dry climate scenario, an increase in $5.8 \%$ for the wet scenarios, and a decrease of $1.3 \%$ for the temperature warming only cases relative to the 1985-1998 levels.

Vicuna [13]also examined the impacts of climate change on high elevation hydropower in California, particularly in the Sierra Nevada region. This study examined a hydroelectric system consisting of 11 hydropower reservoirs operated by the Sacramento Municipal Utility District using climate change data from four global climate models (GCMs) and emissions scenarios. This study predicted hydropower generation to be reduced by $10 \%$ for two of the climate change scenarios, but increased by similar levels for the other climate change scenarios.

Other studies have also been performed. Wang [14] examined the vulnerability of hydropower generation to climate change in China, Schaefli [15] examined impacts of climate change on hydropower in the Swiss Alps. Mimikou [16] performed one of the first studies on this topic for a multipurpose reservoir in Greece and Robinson [17] also performed one of the first studies on this topic for systems in the southeast U.S. The topic of climate change impacts on hydropower have been discussed in many papers regarding the future role of hydropower in a climate affected system [18-20] . 
Overall, the topic of climate change impacts on hydropower has been examined for many regions from a wide range of perspectives such as generation and hydropower plant revenue. While there are many studies on the topic, a key aspect that is currently missing from the literature on this topic is the implications of changes in hydropower generation on the electricity system, greenhouse gas emissions, and electricity system operation.

Translating the impacts of climate change affected runoff on hydropower generation to electricity system emissions and operation impacts requires coupling of climate models and reservoir models with a detailed electric system dispatch model. This study integrates these types of models to provide insight into the impacts of climate change on hydropower generation and the electricity system, and their implications for carbon reduction strategies for the electricity system.

\section{Approach}

\subsection{Electric Grid Modeling}

The electric grid is modeled using the Holistic Grid Resource Integration and Deployment (HiGRID) model [21], developed by the University of California, Irvine. The HiGRID model is a large scale, integrated model of the electricity system which captures changes in technical and economic aspects of the system including but not limited to grid resource dispatch, grid resource operation, greenhouse gas and criteria pollutant emissions, and the levelized cost of electricity due to a wide variety of perturbations.

This model has been used to examine perturbations such as increased variable renewable penetration [21], electrification and grid-integration of light-duty transportation through plug-in vehicles, $[22,23]$ and increased water infrastructure-related electric loads due to the reliance on alternative water supply measures to secure water resource supplies under climate change [24]. For this particular study, the perturbation of hydropower generation in a future climate is studied.

Hydropower generation in the HiGRID model is determined using the model developed by Eichman [25], which takes into account the generation profiles of different types of hydropower, including:

- $\quad$ Run-of-the-river: Non-dispatchable hydropower generation consisting of turbines placed in running streams.

- Conventional: Dispatchable hydropower generation consisting of an upper reservoir and turbines placed at the bottom of a gravity head. Typically on-stream.

- $\quad$ Pumped: Dispatchable hydropower generation consisting of both an upper and lower reservoir with turbines placed at the bottom of a gravity head, which can generate or store electricity depending on need. Note that not all pumped hydropower plants are on-stream, some are isolated from natural river networks. 
The inflow inputs to the relevant hydropower modules are described in the following section. More details on the HiGRID model and the hydropower module specifically are available from Eichman [21].

\subsection{Water Reservoir Modeling}

This study utilizes the water reservoir network model employed by Tarroja [24] for the network of major surface reservoirs in California (see also [26-28]). This model utilizes temporally resolved inflow and demand profiles for individual reservoirs with rules for the release and storage of water which have been calibrated from historical data for a 10-year period from 2000-2010. This 10-year period is the baseline case which is perturbed to represent other cases such as climate change.

The water reservoir model takes into account 13 major reservoirs which provide both water resources and electric power to California through the use of hydropower. More detail on the model development and details are provided by Tarroja [24]. All of these reservoirs are based on in-stream hydropower, and this does not include off-stream pumped hydropower reservoirs. In addition, each reservoir has a minimum fill level below which it can no longer produce any electric power or electric grid ancillary services. In this study, we use the dead pool reservoir level as the minimum, which represents the capacity where the height of the water level falls below the intake structures for the hydropower plants. Below this level, water cannot be extracted from the reservoir using gravity. For this model, minimum fill levels from UC Davis [29] were used with the exception of Lake Mead, which uses the physical minimum fill level based on the height of the lowest intake to the hydropower plant as described by the National Park Service [30], and San Luis, which uses a level specified by the U.S. Bureau of Reclamation [31].

The reservoirs included in the model, along with their total water storage capacities, hydropower capacities, and minimum fill levels are presented in Table 1. Note that for Lake Mead, which supplies power to California, Nevada, and Arizona, the total capacity devoted to California is set at $55.8 \%$, as determined by the CEC for 2014 [32].

It is important to note that this list of reservoirs does not include all of the surface reservoirs which provide hydropower to California, but this system of reservoirs is selected to be representative of the overall trends of hydropower generation in the state. These reservoirs are geographically diverse with each located in different watersheds which allow capturing of the influence of climate change on precipitation and runoff in different regions across the state. Additionally, these surface reservoirs are also the major reservoirs monitored by the California Department of Water Resources for water capacity.

To translate the impacts of climate change on inflows and reservoir levels to that on the entire hydropower generation profile of California, two steps are taken. First, the set of major reservoirs listed is modeled as representing the aggregate behavior of large on-stream hydropower plants, or "conventional hydro" in the HiGRID model. This means that the percentage changes in the generation 
profile of the listed reservoirs is taken to be the percentage changes in the generation profile of the all large hydropower reservoirs in the state. Second, the total percentage changes in overall inflow due to climate change is applied as percentage changes in the inflow input into the simulation module for the run-of-the-river hydropower.

Combined, both of these steps will capture the trends of climate-change impacted inflows on hydropower generation and more importantly, their impact on electric system operation.

\subsection{Reservoir Inflows under Climate Change}

The impacts of climate change on reservoir inflows have been determined using CMIP5 model simulations of the future climate [33]. The simulations include two Representative Concentration Pathway scenarios (RCP): RCP 4.5 and RCP 8.5. These two RCPs represent moderate and strong radiative forcing conditions for the IPCC $5^{\text {th }}$ Assessment Report (IPCC 2013). We have used model simulations downscaled and bias corrected by the Scripps Institute for Oceanography [34-36]. The simulations used is based on an average of the outputs from 10 climate models: (Access1, CanESM2, CCSM4, CESM1-BGC, CMCC-CMS, CNRM-CM5, GFDL-CM3, HadGEM2-CC, HadGem2-ES, and MIROC5). Variable Infiltration Capacity (VIC) Model is then used to obtain hydrology projection and river flow estimation [4]. In this study, the projection period is selected as 2040-2050, and the difference in reservoir inflows between future simulations and the baseline period of 2000-2010 was applied as a modification to actual reservoir inflow data obtained from DWR [37] and USGS [38]. The model simulations are based on the ensemble mean of the above climate models.

It is also important to note that for this study, the demand for water from the reservoirs considered remains constant as that in the baseline case. The impacts of potential additional demand for water in California due to climate change are not considered here to isolate the impact of climate change on reservoir inflows and the need for more precise demand predictions.

\subsection{Scenarios}

For this study, three primary scenarios are considered from the perspective of water inflows:

- $\quad$ STA refers to "Standard" reservoir inflow profiles which follow historical trends for the reservoirs in question, but with year 2050 population.

- $\quad$ RCP 4.5 refers to reservoir inflow profiles modified by the future runoff simulations for the reservoirs considered for the RCP 4.5 from the Intergovermental Panel on Climate Change Assessment Report 5 (IPCC AR5), using the years of 2040-2050. Population is set at the year 2050 level.

- $\quad$ RCP 8.5 refers to reservoir inflow profiles modified by the future runoff simulations for the reservoirs considered for the RCP 8.5 from the Intergovermental Panel on Climate Change Assessment Report 5 (IPCC AR5), using the years of 2040-2050. Population is set at the year 2050 level. 
The latter two cases are compared to the former to examine the impacts of climate change on hydropower generation and grid operation.

From the perspective of electric grid energy mix, each of the water-inflow scenarios are evaluated on an electricity system with a renewable penetration level of $50 \%$. This means that the amount of available renewable generation is enough to meet $50 \%$ of the energy of the electric load demand with renewable resources, including transmission and distribution losses. The renewable capacities by type for this renewable mix are as follows:

\subsection{Metrics}

To examine the effect of climate-change impacted hydropower generation, certain metrics for the behavior or performance of the surface water reservoirs and the electric grid are measured. These are described as follows:

- Percentage of Days Below Minimum Fill: This represents the number of days that each reservoir is below its minimum fill level for providing hydropower generation.

- Average Fill Level: This represents the average fill level of each of the reservoirs over the time period of examination.

- Normalized Inflow Volume: This represents the sum of the reservoir inflow over the 10-year period to all reservoirs combined comparing the climate-change impacted and historical cases. This serves as a means for comparing the overall water availability to the reservoirs in each case.

- Standard Deviation of Reservoir Fill: This is a statistical representation of the variability of the fill levels of each reservoir over the time period of examination, as a percentage of the fill level for the corresponding reservoir.

- Grid Greenhouse Gas (GHG) Emissions: This represents the annual amount of greenhouse gas emissions produced by the electricity system, taking into account both in-operation emissions and upstream emissions for fuel processing.

- Load-Follower (LF) Power Plant Capacity: This represents the capacity of non-hydropower dispatchable power plants which are tasked with balancing the variations in the net load demand profile. In California, this task falls on a fleet of combined cycle power plants, and this metric represents the required capacity of these units to be installed to keep the grid balanced.

- The net load demand profile is the total electric demand profile minus the generation profile of renewable resources, which are considered to be must-take. While base-load resources meet some of the energy of the net load demand, load-following power plants must meet energy needs and balance temporal variability.

- Natural Gas Fuel Use: This represents the total usage of natural gas fuel by the electric grid. 
- Levelized Cost of Electricity: This represents the price at which electricity needs to be priced for all participating resources on the electric grid to recover their costs.

\section{Results}

\subsection{Reservoir Behavior and Hydropower Generation Impacts}

The effects of climate-change impacted reservoir inflows on the average fill levels of surface water reservoirs considered here is presented in Figure 1, with the normalized inflow volume to all reservoirs combined presented in Figure 2. The standard deviation of reservoir fill levels presented in Figure 3 and the percentage of days below minimum hydropower generation fill level is presented in Figure 6 for the 2050 STA, AR5 RCP 4.5, and AR5 RCP 8.5 cases:

Based on the latest available future climate simulations (AR5), projected runoff causes varying impacts to the average 10-year reservoir fill levels considered here. On average, the RCP 4.5 simulations show that reservoir levels drop slightly compared to historical levels, whereas the RCP 8.5 simulations indicate reservoirs remain at similar average reservoir fill levels. The extent of the change in average reservoir fill levels differs between reservoirs due to a number of factors such as different demand levels, inflow levels, and the spatial variability of climate change impacts.

The RCP 4.5 average reservoir fill levels are slightly lower than historical even though the total amount of inflow to these reservoirs is slightly larger compared to historical levels. Figure 2 shows that the RCP 4.5 shows about 3\% more total inflow to these reservoirs compared to historical (baseline) period, and the RCP 8.5 case indicates about $7 \%$ more total inflow. While the overall inflow amounts are greater, however, the RCP 4.5 and RCP 8.5 simulations show a larger amount of spilled volume compared to historical cases, causing the net effective inflow to these reservoirs to be slightly lower in the RCP 4.5 simulations and nominally equivalent in the RCP 8.5 Simulations. Spilled volume occurs when the surface water reservoirs reach capacity and are unable to store any more water under threat of dam loading or failure. In this case, water is released from the reservoir through an emergency outlet which bypasses the hydropower turbines. Spilled volume does not contribute to hydropower generation, and essentially represents wasted potential.

The increased spillage of available water inflow occurs due to the increased variability of the available water inflow under future emission scenarios. While the overall inflow volume is predicted to be slightly higher according to these latest climate simulations, this inflow enters streams and reservoirs in more extreme precipitation events. Therefore, events of high precipitation occur which saturate reservoir capacities and cause spillage, followed by longer dry periods. This is exemplified by the standard deviation of reservoir fill in Figure 3. Note that for this metric, it is only relevant to compare across the climate scenarios for each reservoir, not across reservoirs, since these are fill levels which are normalized by reservoir capacity. In these results, the standard deviation for reservoir fills tend to be increased - sometimes significantly so - in the future climate compared to historical levels. A time series 
example of spill events and increased variability under climate change is presented in Figure 4 for the Don Pedro reservoir and Figure 5 for the Pine Flat reservoir:

The time series of the reservoir fill profiles show a few key characteristics. Spill events can be located in these profiles at the points where the reservoir fill reaches or rises very close to $100 \%$ followed by an immediate drop in fill levels. As reservoirs fill, water is spilled to prevent overloading of the dam capacities. In some cases, additional water is spilled to reduce reservoir fill levels below $100 \%$ in order to make room for additional high inflow events which are forecasted to occur in the near-term after a reservoir has reached capacity. These are the sudden drops in reservoir fill levels that occur after reaching $100 \%$, and in many cases multiple such events may occur in succession during extended periods of high inflow, as evidenced by the oscillation-like behavior of the Don Pedro reservoir fill centered on the 1200 day and 2000 day mark. Note that spill events were much less frequent in historical data. Increased variability, as implied by the standard deviation metrics, are shown explicitly in the time series profiles by the increased range spanned reservoir fill levels in the climate-change impacted cases.

The increased variability in reservoir fill levels also shows that in some cases, the extended dry periods that occur after large precipitation events and spilling can cause reservoir levels to occasionally reach low levels between precipitation events. This is shown in the Pine Flat time series, where the RCP 4.5 and RCP 8.5 simulations show occasional drops in reservoir fill levels below the minimum fill level limits below which hydropower generation must be shut off temporarily. A plot of the percentage of days that each reservoir is below its minimum fill level for hydropower generation is presented in Figure 6:

Under historical reservoir inflows, 12 of the 13 reservoirs considered here did not show any days below their minimum hydropower generation fill level. Between 2002 and 2010, hydropower generation composed between $10.8 \%$ and $21.1 \%$ of the total annual electric generation for California. While hydropower generation was reduced towards the end of the period, this caused a reduction in hydropower generation but not necessarily a shut-down of major hydropower plants due to insufficient fill levels. In the STA case, Castaic Lake was the only reservoirs which showed days below minimum hydropower generation fill levels due to a very high minimum fill level and large inactive capacity.

Considering future simulated inflows, however, 6 of the 13 reservoirs exhibited at least a few days below minimum for the RCP 4.5 simulations and 5 of 13 reservoirs for the RCP 8.5 simulations. With the exception of Castaic and Millerton Lake, the amount of days below minimum fill level as less than $10 \%$. These impacts are due to the increased variability of inflow under climate change, and occur even though the total inflow volume was higher than historical levels in these cases. Additionally, with respect to hydropower generation, the reservoirs where fill levels drop below minimum levels for any amount of time have relatively small hydropower capacities relative to others in the reservoir set considered here.

These characteristics in hydropower reservoir behavior translate into impacts on overall annual hydropower generation as presented in Figure 7: 
With the impacts present in the latest climate data, the average overall hydropower generation over the 10-year period examined here is not significantly affected, under the approach of the 13 large reservoirs being representative of trends in statewide hydropower generation. In the RCP 4.5 simulations, average annual hydropower generation is decreased by $1.5 \mathrm{TWh}$ or $3.1 \%$ from historical. Based on RCP 8.5 simulations, average annual hydropower generation is increased by an almost negligible amount of 0.40 TWh or $0.82 \%$ from historical, which is nominally equal. Based on CMIP5 simulations climate change and variability is expected to increased total inflow, yet these trends occur due to the effects of spillage and variability. While the average annual generation over the 10 -year period is relatively unchanged, the increased variability of inflow and reservoir fill with in a changing climate is expected to result in significant year-to-year variability in hydropower generation, as shown in Figure 8:

During any given year, annual hydropower generation can either be significantly less or significantly more than historical levels. The electricity system needs to be prepared to adapt to this increased variability especially with respect to resource planning.

\subsection{Electric Grid Performance Impacts}

The difference between the performance of the electric grid on the four metrics of greenhouse gas emissions, load-following capacity, natural gas fuel use, and the levelized cost of electricity is presented as percentage differences in Figure 9 and as absolute differences in Figure 10:

Climate-change impacted hydropower generation causes greenhouse gas emissions to increase by a small amount of $1.15 \mathrm{MMT}$ CO2e for the RCP 4.5 simulations and 0.54 MMT CO2e for RCP 8.5 simulations, representing percentage increases of $2.35 \%$ and $1.11 \%$ compared to the $50 \%$ RE case with historical hydrology. For the RCP 4.5 simulations, the increase in greenhouse gases is primarily due to additional natural gas use in order to compensate for the slightly decreased hydropower generation caused by spill events reducing the net effective inflow to surface water reservoirs. Note that spilled volume does not contribute towards electricity generation.

The RCP 8.5 simulations, while displaying similar levels of average annual hydropower generation to historical cases, still shows a very small increase in greenhouse gas emissions. This occurs due to how the extreme variability of hydropower under climate change impacts the dispatch and operation of fossil-fueled natural gas power plants. During very dry years, the shortfall in hydropower generation is compensated for by increased natural gas-fueled generation above the level provided in a typical year. Since hydropower generation is carbon-free in operation and other resources do not have the dispatchability or flexibility required to perform load-following services for the electric grid (especially with renewable resources), its role is replaced by natural gas combined cycle or simple cycle power plants. Higher energy needs from balancing generation resources tends to decrease the overall efficiency of the balancing generator fleet. More efficient power plants are typically dispatched on a regular basis to meet frequently occurring load levels, but less-frequent elevated load levels are satisfied by less efficient load-following power plants and peaking power plants as the more efficient units have already been dispatched. This effect is observed in RCP 8.5 simulations during the dry years, particularly 
with peaking generators. While the amount of energy provided by peaking generation is relatively small in the overall generation portfolio, the fleet-wide efficiency of peaking power plants was $28.7 \%$ in the RCP 8.5 simulations compared to $39.6 \%$ in the STA case, contributing to a small increase in greenhouse gas emissions even though hydropower generation was only very slightly higher than historical levels. The results for greenhouse gases are reflected in those for natural gas fuel use. The percentage increases are similar for both RCP 4.5 and RCP 8.5 simulations compared to historical cases, with the absolute increases being 22.3 Million MMBTU and 10.7 Million MMBTU respectively.

This shortfall is not equally recovered during wet years. During wet years, the balancing power plant fleet is more efficient in that these units operate closer to their design point efficiency. In the STA case, however, balancing generators are already operating at close to peak efficiency, therefore wet years do not cause these units to operate with significantly efficiencies since there is not much of a margin for improvement. Dry years, however, cause more significant de-rates in efficiency as balancing power plants since these units start to operate at significant part-load conditions.

The increased reliance on natural gas generation during dry years above typical levels also requires a very slight increase in load following power plant capacity compared to historical needs. These increases are very small compared to the total installed capacity needs for natural gas power plants: $640 \mathrm{MW}$ in the RCP 4.5 simulations and $320 \mathrm{MW}$ in the RCP 8.5 simulations, representing increases of $1.79 \%$ and $0.894 \%$, respectively. For reference, the installed load following capacity needs of system is $35.8 \mathrm{GW}$ in the historical hydrology case with $50 \% \mathrm{RE}$. While small, this result does show that hydropower variability can impact not only energy provision, but also capacity planning.

These impacts are exemplified by examining a snapshot of the time series plots of the $50 \% \mathrm{RE}$ case for the two different water inflow conditions, presented in Figure 11 for STA, Figure 12 for RCP 8.5 in a dry year, and Figure 13 for RCP 8.5 in a wet year.

With $50 \%$ renewable penetration, there are significant dynamics in the net load profile which dispatchable resources must respond to. There is a mix of load-following and peaking power plant generation in addition to hydropower to meet the portion of the load that is not satisfied by renewables or base load/geothermal. In the STA case, hydropower generation is available to help manage these dynamics. Hydropower generation is also dispatched to provide the most generation during the early evening hours when solar power is ramping down and the raw load demand is ramping up, causing peak net load conditions on the electric grid. Additionally, hydropower generation also allows reduced use of the load following power plant fleet and therefore reduced use of fossil fuels. Peaking power plants, which balance the very fast variations in the net load demand, also provide generation during these time periods.

In the RCP 8.5 dry year plot (Figure 12), the available hydropower is dispatched to manage renewable dynamics to the extent possible, but with reduced volume available for hydropower generation. This manifests in drops in the hydropower generation profile, as well as increases in loadfollowing and peaking generation as explained previously. This increase in balancing power plant generation and the corresponding efficiency drop causes increased greenhouse gas emissions. 
In the RCP 8.5 wet year plot Figure 13), there is a significant amount of hydropower generation which is beneficial from a greenhouse gas emissions standpoint. In this case, however, these power plants do not have as much flexibility to turn down when needed to utilize renewable generation due to the extreme inflow events caused by climate change. With extreme inflow levels, hydropower reservoirs must release large amounts of water, with the options to do so being increasing hydropower generation or spilling volume. Preference is placed on hydropower generation since this use obtains revenue for the power plant and spilling volume is minimized. This causes hydropower generation to operate closer to a base-load resource during these events, limiting the uptake of renewable generation.

The impacts of climate change on hydropower generation also have slight economic impacts, due to increased natural gas usage and capacity installations. These translate to increases in $0.40 \%$ and $0.16 \%$ in the RCP 4.5 and RCP 8.5 simulations respectively, or $0.58 \$ / \mathrm{MWh}$ and $0.23 \$ / \mathrm{MWh}$ in absolute units. These are small impacts, but can increase with increases the price of natural gas. However, these costs primarily take into account the costs of fuel, operation and maintenance, and new capacity investments which are small in these results. Additional cost implications may exist in the future which can affect the final cost of electricity due to impacts of hydropower variability.

The authors acknowledge that climate models are subject to uncertainties due to model physics, initial and boundary conditions, and model parameters [39-46]. Particularly, uncertainties of simulated climatic extremes are substantial $[47,48]$. Uncertainties in climate models can affect simulations results. For this reason, the focus of this paper is on examining the response of the electricity system to perturbations of climate change on hydropower and to demonstrate a framework for investigating this topic. Today's individual climate models cannot be used for projection of daily or annual conditions in specific times in future. Instead, they should be used to assess system's behavior/response under prescribed climate scenarios.

\section{Conclusions}

This study combined a surface water reservoir network model with an electric grid dispatch model for the state of California and subjected it to examine the impacts of climate change and variability on hydropower generation, electric grid performance and operation. The key takeaways are as follows:

1. Climate change is primarily expected to increase hydropower reservoir inflow variability but not significantly impact overall inflow volume. According to the latest inflow projections based on downscaled $5^{\text {th }}$ Assessment Report climate model simulations, total inflows to hydropower reservoirs in California are either not expected to change or actually increase slightly in contrast to previous reports. However, while overall volume may be similar or higher, the delivery of this volume is significantly more variable than the historical average, which has many implications for hydropower generation.

\section{Increased overall inflow volume does not necessarily result in more hydropower} generation. Future climate projections exhibit more variability relative to the historical period, with more extremes broken up by longer dry periods. During extreme precipitation events, reservoirs are 
forced to spill water without generating power from that volume in order to prevent overloading of the dam structures, and are therefore not necessarily able to take advantage of increased reservoir inflow. During the following extreme dry period, reservoir levels drop to lower than historical average levels which can limit hydropower generation. Therefore, even though the RCP 4.5 and RCP 8.5 simulations exhibited higher water inflow volumes for the reservoirs, this did not result in any significant increase in hydropower generation, with the RCP 4.5 simulations showing slightly decreased hydropower generation and the RCP 8.5 case showing similar hydropower generation compared to historical levels.

\section{Increased variability in reservoir inflow under future emission scenarios still causes slight} increases in fuel use and greenhouse gas emissions, despite overall inflow volume being higher. Because of high variability in inflows and longer dry periods, the grid model showed increased reliance on natural gas fueled power plants to balance the load occurs to compensate for the shortfall in hydropower generation. During these periods, less efficient, load-following and peaking power plants are dispatched to meet high loads and regulate renewable variability since more efficient units have already been dispatched. This decreases the efficiency of the overall natural gas power plant fleet compared to the case with historical hydrology. During the extreme wet, this effect is not counterbalanced since balancing power plants already operated close to their design point efficiency during historical cases, therefore the margin for efficiency increase during wet years is smaller than the turndown and efficiency loss experienced during dry years.

Overall, while the magnitude of these impacts can vary, impacts of climate change of hydropower generation due to climate change needs to be taken into account for future planning. The integration of a surface reservoir network model with an electric grid dispatch model shows promise for being able to capture these impacts to inform carbon reduction planning.

With respect to greenhouse gas reduction goals in California, the energy system needs to evolve to be capable of absorbing the increased variability of hydropower generation in order to make the best use of this carbon-free (in operation) resource. Hydropower may need to be treated as a variable resource such as solar and wind but over a longer timescale, and better management of water resources and potentially increased storage may be needed to mitigate this variability. Alternatively, hydropower generation may need to be displaced for by other carbon free generation and systems to build resilience into the system.

\section{$\underline{\text { 6. Acknowledgments }}$}


The authors also like to thank the California Energy Commission for having funded the development of the energy system modeling tools used in this study through previous grants (CEC PIR08-33). The authors are also gracious to the National Science Foundation for having provided funding for the development of the water reservoir models through project no. EAR-1316536.

\section{References}

1. Williams, J.H., et al., The Technology Path to Deep Greenhouse Gas Emissions Cuts by 2050: The Pivotal Role of Electricity. Science, 2012. 335(6064): p. 53-59.

2. Database of State Incentives for Renewables \& Efficiency, 2013, U.S. Department of Energy.

3. Brown, J., Executive Order B-30-15, 2015, California Office of the Governor.

4. Cayan, D.R., et al., Future dryness in the southwest US and the hydrology of the early 21st century drought. Proceedings of the National Academy of Sciences, 2010. 107(50): p. 2127121276.

5. Barnett, T.P., et al., Human-Induced Changes in the Hydrology of the Western United States. Science, 2008. 319(5866): p. 1080-1083.

6. Zhu, T., M.W. Jenkins, and J.R. Lund, ESTIMATED IMPACTS OF CLIMATE WARMING ON CALIFORNIA WATER AVAILABILITY UNDER TWELVE FUTURE CLIMATE SCENARIOS1. JAWRA Journal of the American Water Resources Association, 2005. 41(5): p. 1027-1038.

7. Mazdiyasni, O. and A. AghaKouchak, Substantial increase in concurrent droughts and heatwaves in the United States. Proceedings of the National Academy of Sciences, 2015. 112(37): p. 1148411489.

8. Bales, R.C., et al., Mountain hydrology of the western United States. Water Resources Research, 2006. 42(8): p. n/a-n/a.

9. AghaKouchak, A., et al., Water and climate: Recognize anthropogenic drought. Nature, 2015. 524: p. 409-411.

10. Madani, K. and J. Lund, Estimated impacts of climate warming on California's high-elevation hydropower. Climatic Change, 2010. 102(3-4): p. 521-538.

11. Hamlet, A., et al., Effects of projected climate change on energy supply and demand in the Pacific Northwest and Washington State. Climatic Change, 2010. 102(1-2): p. 103-128.

12. Kao, S.-C., et al., Projecting changes in annual hydropower generation using regional runoff data: An assessment of the United States federal hydropower plants. Energy, 2015. 80(0): p. 239-250.

13. Vicuna, S., et al., Climate change impacts on high elevation hydropower generation in California's Sierra Nevada: a case study in the Upper American River. Climatic Change, 2008. 87(1): p. 123-137.

14. Wang, B., et al., Vulnerability of hydropower generation to climate change in China: Results based on Grey forecasting model. Energy Policy, 2014. 65(0): p. 701-707.

15. Schaefli, B., B. Hingray, and A. Musy, Climate change and hydropower production in the Swiss Alps: quantification of potential impacts and related modelling uncertainties. Hydrol. Earth Syst. Sci., 2007. 11(3): p. 1191-1205.

16. Mimikou, M.A. and E.A. Baltas, Climate change impacts on the reliability of hydroelectric energy production. Hydrological Sciences Journal, 1997. 42(5): p. 661-678.

17. Robinson, P.J., Climate change and hydropower generation. International Journal of Climatology, 1997. 17(9): p. 983-996. 
18. Gaudard, L. and F. Romerio, The future of hydropower in Europe: Interconnecting climate, markets and policies. Environmental Science \& Policy, 2014. 37(0): p. 172-181.

19. Bahadori, A., G. Zahedi, and S. Zendehboudi, An overview of Australia's hydropower energy: Status and future prospects. Renewable and Sustainable Energy Reviews, 2013. 20(0): p. 565569.

20. Jager, H.I., et al., Spatial design principles for sustainable hydropower development in river basins. Renewable and Sustainable Energy Reviews, 2015. 45(0): p. 808-816.

21. Eichman, J.D., et al., Exploration of the integration of renewable resources into California's electric system using the Holistic Grid Resource Integration and Deployment (HiGRID) tool. Energy, 2013. 50(1): p. 353-363.

22. Tarroja, B., et al., The effectiveness of plug-in hybrid electric vehicles and renewable power in support of holistic environmental goals: Part 1 - Evaluation of aggregate energy and greenhouse gas performance. Journal of Power Sources, 2014. 257(0): p. 461-470.

23. Tarroja, B., B. Shaffer, and S. Samuelsen, The importance of grid integration for achievable greenhouse gas emissions reductions from alternative vehicle technologies. Energy, 2015. 87: p. 504-519.

24. Tarroja, B., et al., Evaluating options for balancing the water-electricity nexus in California: Part 2-Greenhouse gas and renewable energy utilization impacts. Science of The Total Environment, 2014. 497-498(0): p. 711-724.

25. Chang, M.K., et al., Buffering intermittent renewable power with hydroelectric generation: $A$ case study in California. Applied Energy, 2013. 112: p. 1-11.

26. van Beek, L.P.H., Y. Wada, and M.F.P. Bierkens, Global monthly water stress: 1. Water balance and water availability. Water Resources Research, 2011. 47(7): p. n/a-n/a.

27. Haddeland, I., T. Skaugen, and D.P. Lettenmaier, Anthropogenic impacts on continental surface water fluxes. Geophysical Research Letters, 2006. 33(8): p. n/a-n/a.

28. Hanasaki, N., S. Kanae, and T. Oki, A reservoir operation scheme for global river routing models. Journal of Hydrology, 2006. 327(1-2): p. 22-41.

29. CALVIN Project Appendix H: Infrastructure, 2001, UC Davis.

30. Storage Capacity of Lake Mead. 2010 [cited 2015 September 21].

31. San Luis Reservoir Low Point Improvement Project Final Appraisal Report, 2006, U.S. Bureau of Reclamation.

32. Facts on California's Use of Hydroelectricity, 2014, California Energy Commission.

33. Taylor, K.E., R.J. Stouffer, and G.A. Meehl, An Overview of CMIP5 and the Experiment Design. Bulletin of the American Meteorological Society, 2012. 93(4): p. 485-498.

34. Pierce, D.W., et al., Improved Bias Correction Techniques for Hydrological Simulations of Climate Change. Journal of Hydrometeorology, 2015. 16(6): p. 2421-2442.

35. Pierce, D.W., D.R. Cayan, and B.L. Thrasher, Statistical Downscaling Using Localized Constructed Analogs (LOCA). Journal of Hydrometeorology, 2014. 15(6): p. 2558-2585.

36. Pierce, D.W., et al., The Key Role of Heavy Precipitation Events in Climate Model Disagreements of Future Annual Precipitation Changes in California. Journal of Climate, 2013. 26(16): p. 58795896.

37. California Data Exchange Center, 2013, California Department of Water Resources.

38. National Water Information System: Web Interface, 2013, U.S. Geological Survey.

39. Wehner, M., Methods of Projecting Future Changes in Extremes, in Extremes in a Changing Climate, A. AghaKouchak, et al., Editors. 2013, Springer Netherlands. p. 223-237.

40. Brekke, L., Barsugli, J., Uncertainties in projections of future changes in extremes., in Extremes in a Changing Climate2013, Springer. 
41. Feddema, J., et al., A comparison of a GCM response to historical anthropogenic land cover change and model sensitivity to uncertainty in present-day land cover representations. Climate Dynamics, 2005. 25(6): p. 581-609.

42. Mehran, A., A. AghaKouchak, and T.J. Phillips, Evaluation of CMIP5 continental precipitation simulations relative to satellite-based gauge-adjusted observations. Journal of Geophysical Research: Atmospheres, 2014. 119(4): p. 2013JD021152.

43. Sillmann, J., et al., Climate extremes indices in the CMIP5 multimodel ensemble: Part 1. Model evaluation in the present climate. Journal of Geophysical Research: Atmospheres, 2013. 118(4): p. 1716-1733.

44. Pascale, S., et al. Analysis of rainfall seasonality from observations and climate models. arXiv, 2014.

45. Cayan, D.R., et al., Climate change scenarios for the California region. Climatic Change, 2008. 87(1): p. 21-42.

46. Brekke, L.D., et al., Significance of model credibility in estimating climate projection distributions for regional hydroclimatological risk assessments. Climatic Change, 2008. 89(3-4): p. 371-394.

47. AghaKouchak, A., et al., Extremes in a Changing Climate2013, Netherlands, Dordrecht: Springer.

48. Zengchao, H., A. AghaKouchak, and T.J. Phillips, Changes in concurrent monthly precipitation and temperature extremes. Environmental Research Letters, 2013. 8. 


\section{Figures}

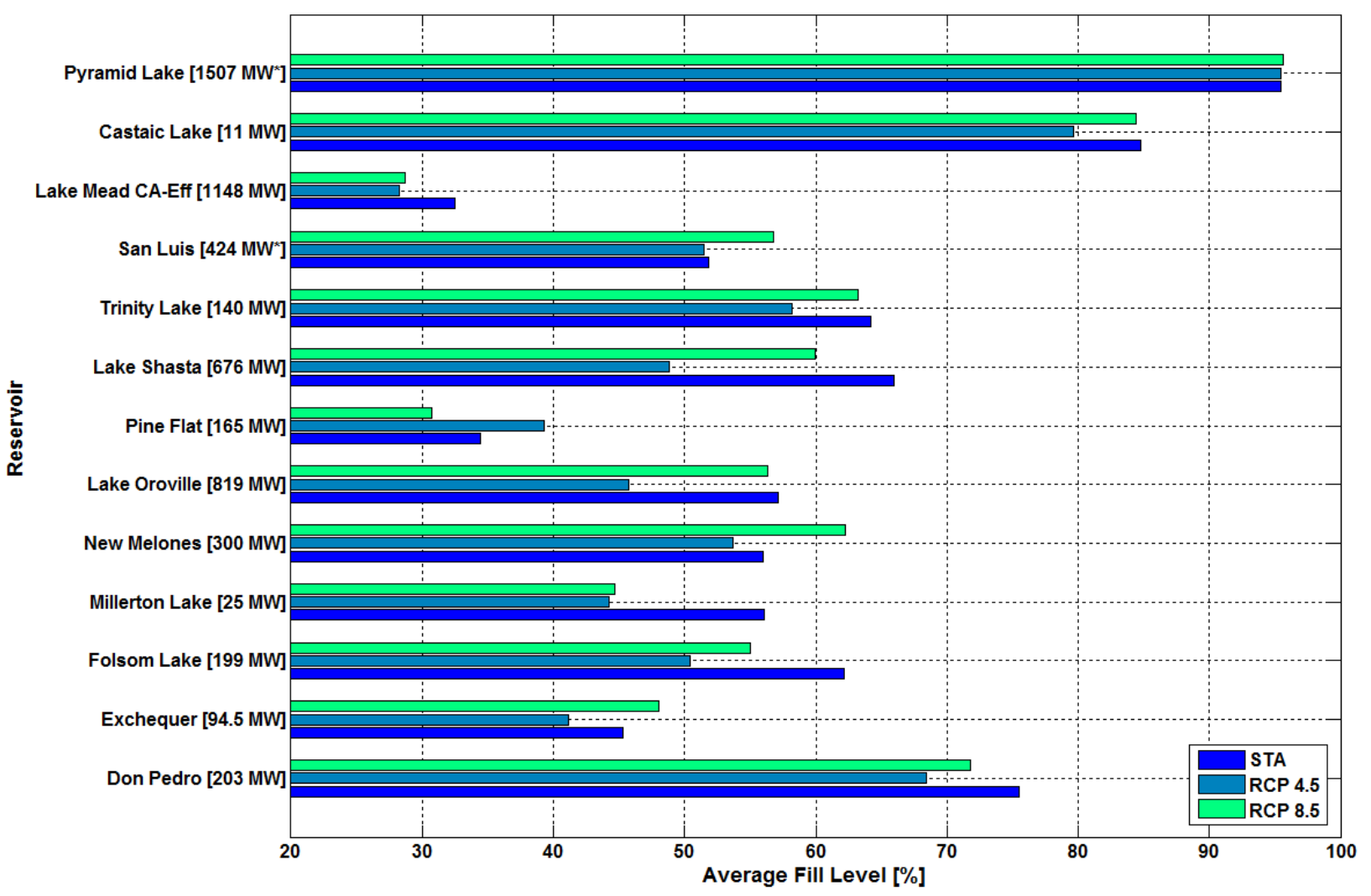

Figure 1- Average Fill Level 


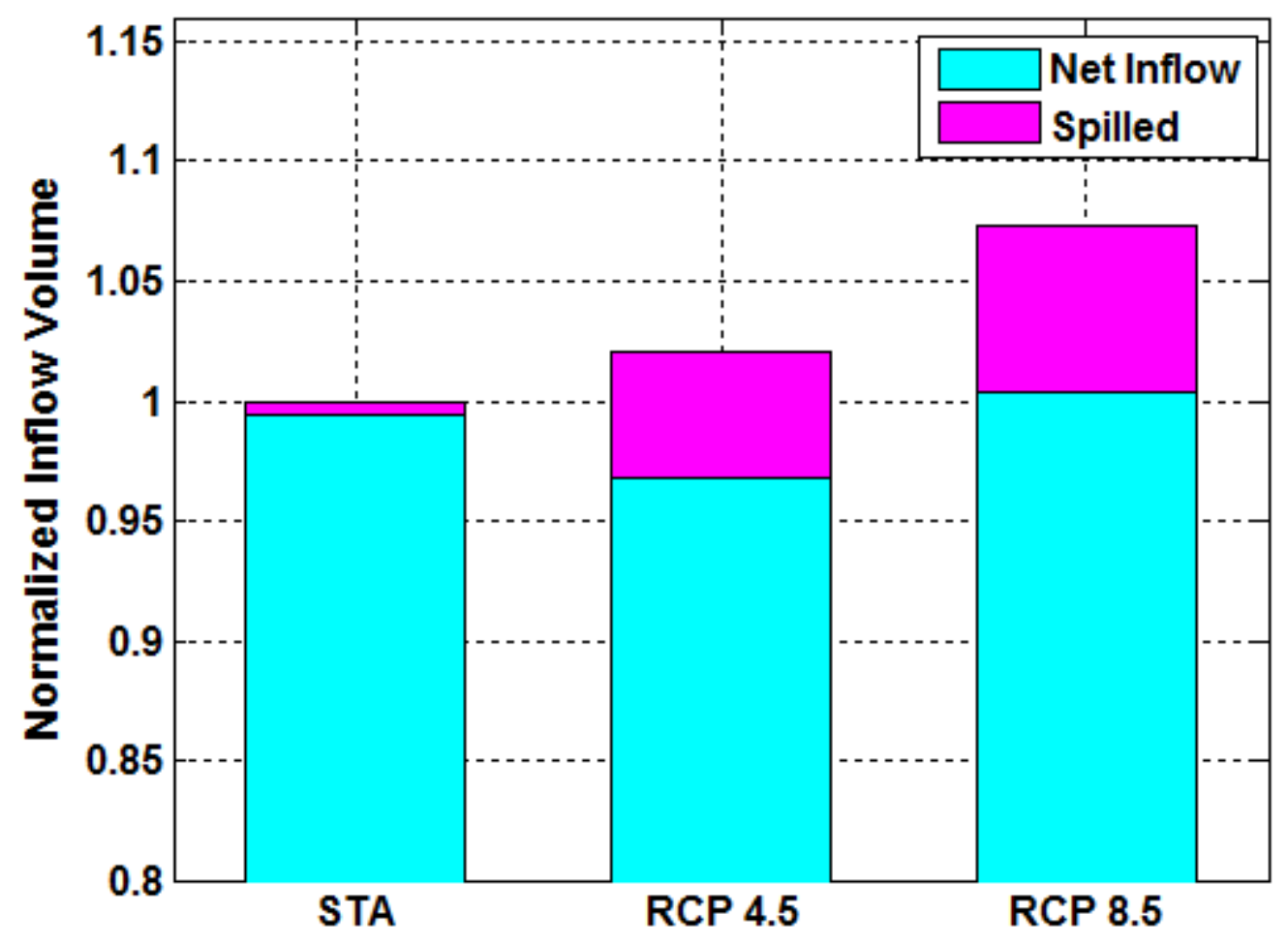

Figure 2 - Normalized Inflow Volume 


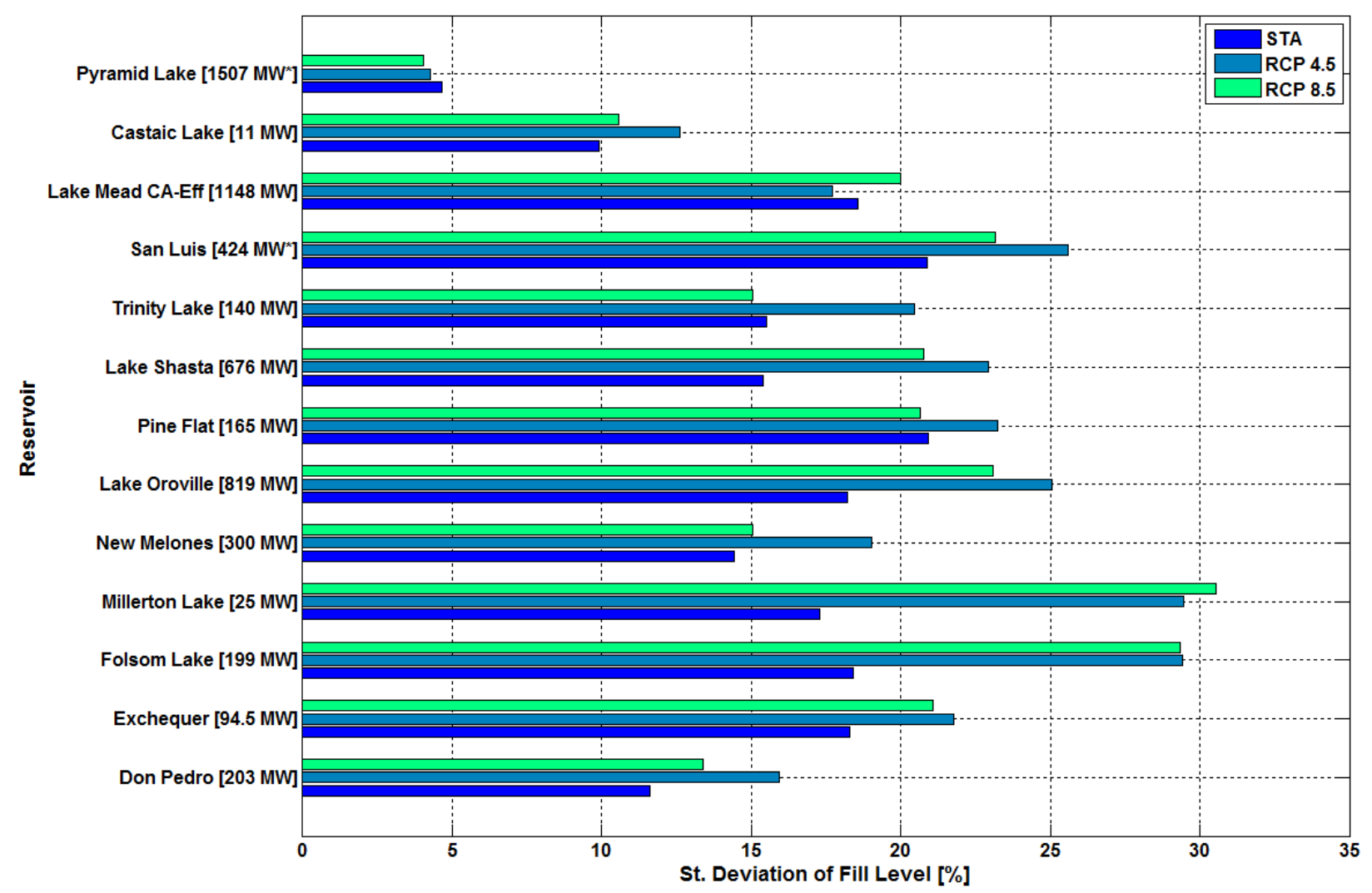

Figure 3 - Standard Deviation of Reservoir Fill Level, Normalized by Capacity for Each Reservoir 


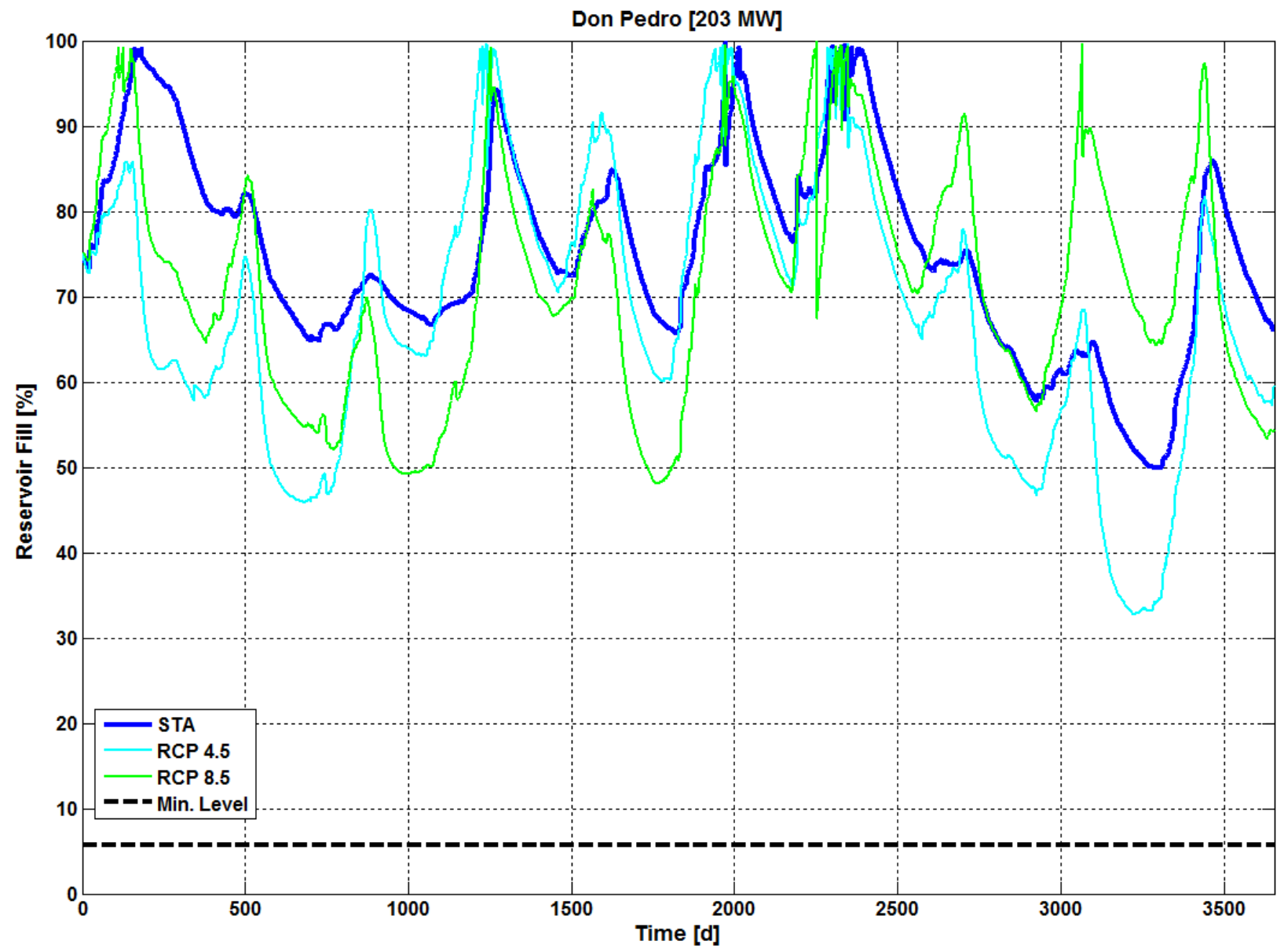

Figure 4 - Don Pedro Reservoir Fill Profiles 


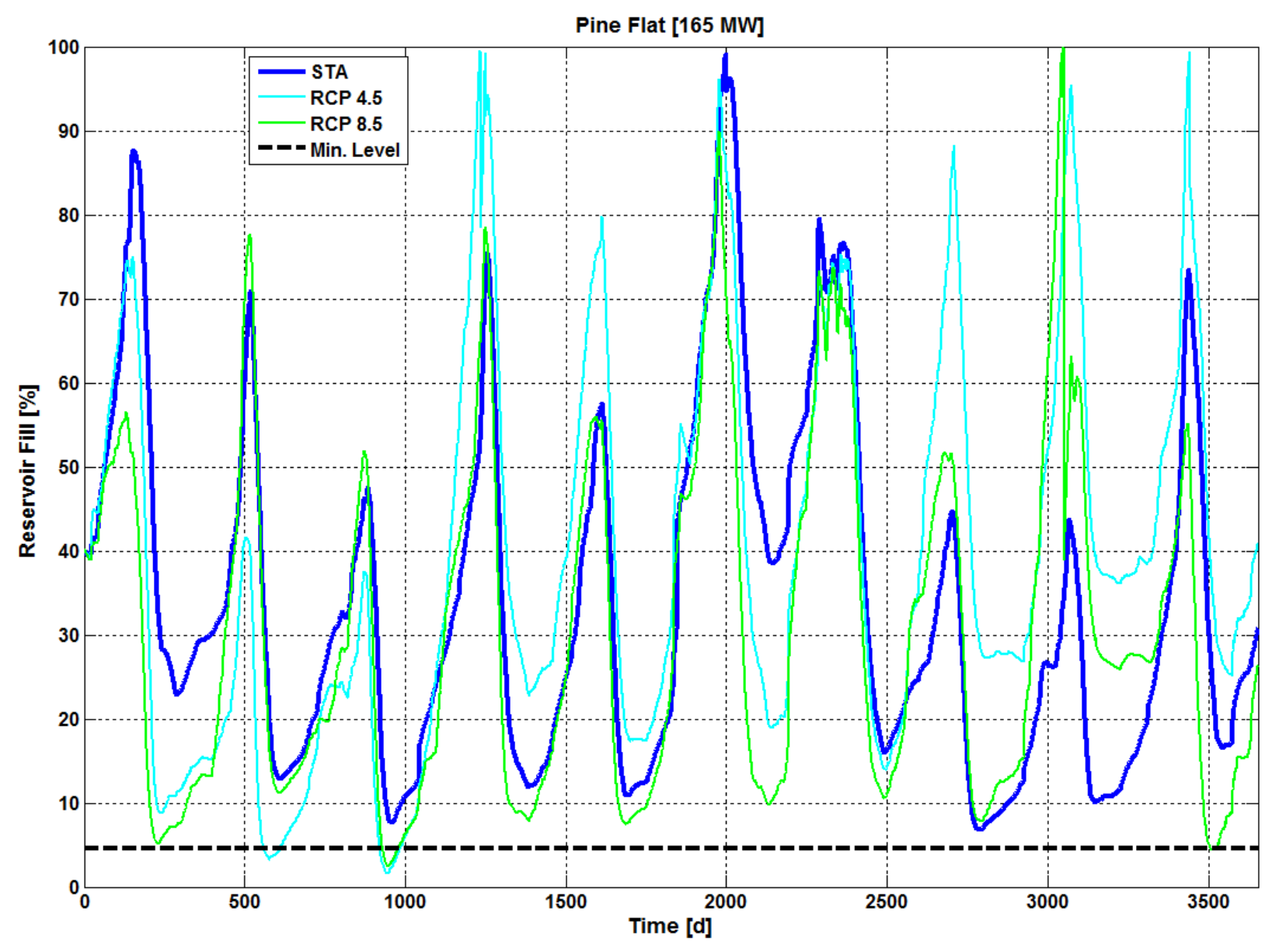

Figure 5 - Pine Flat Reservoir Fill Profiles 


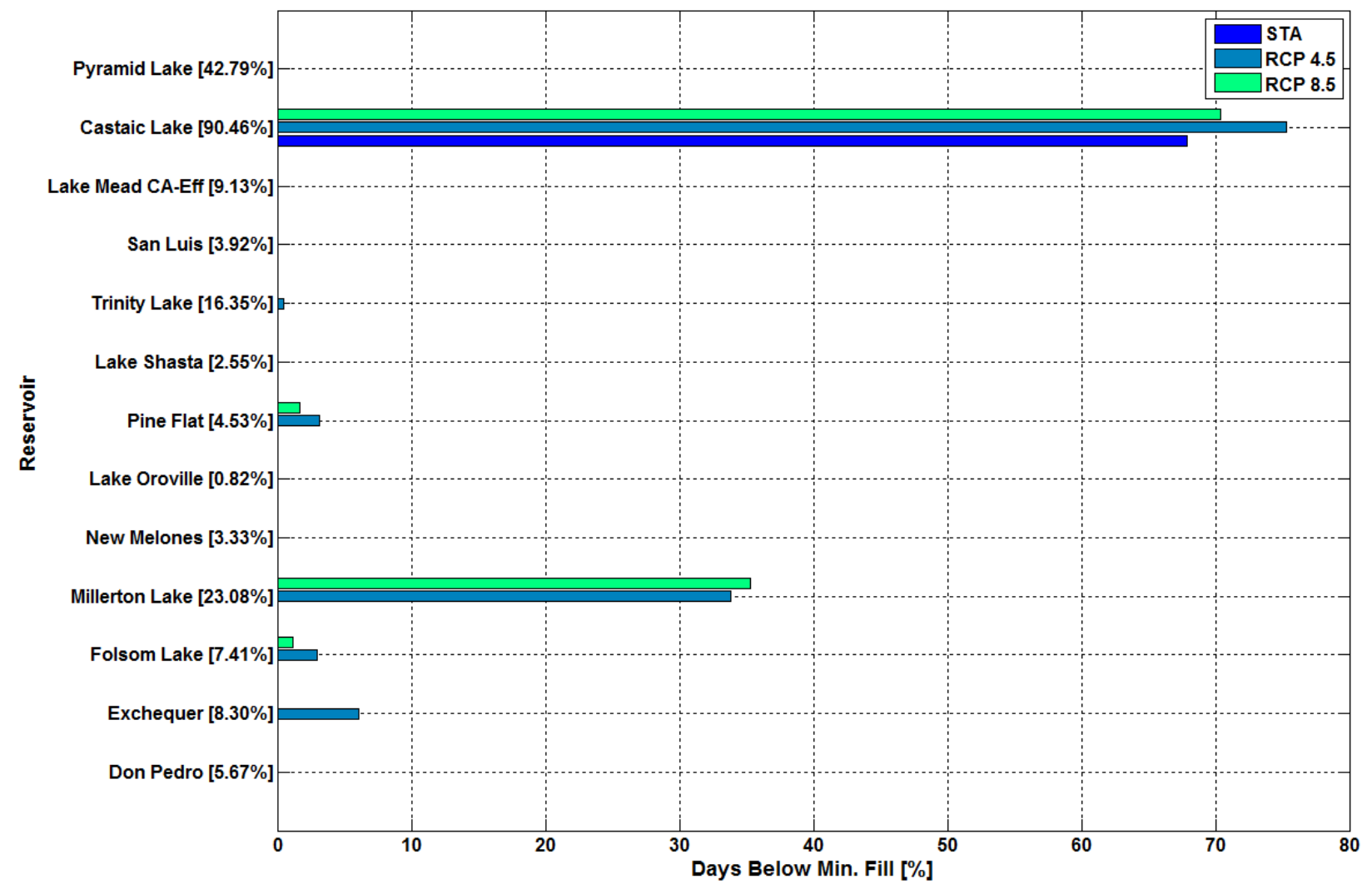

Figure 6 - Percentage of Days Below Minimum Hydropower Generation Fill Level. Bracketed numbers indicate the minimum fill level percentage for the corresponding reservoir. 


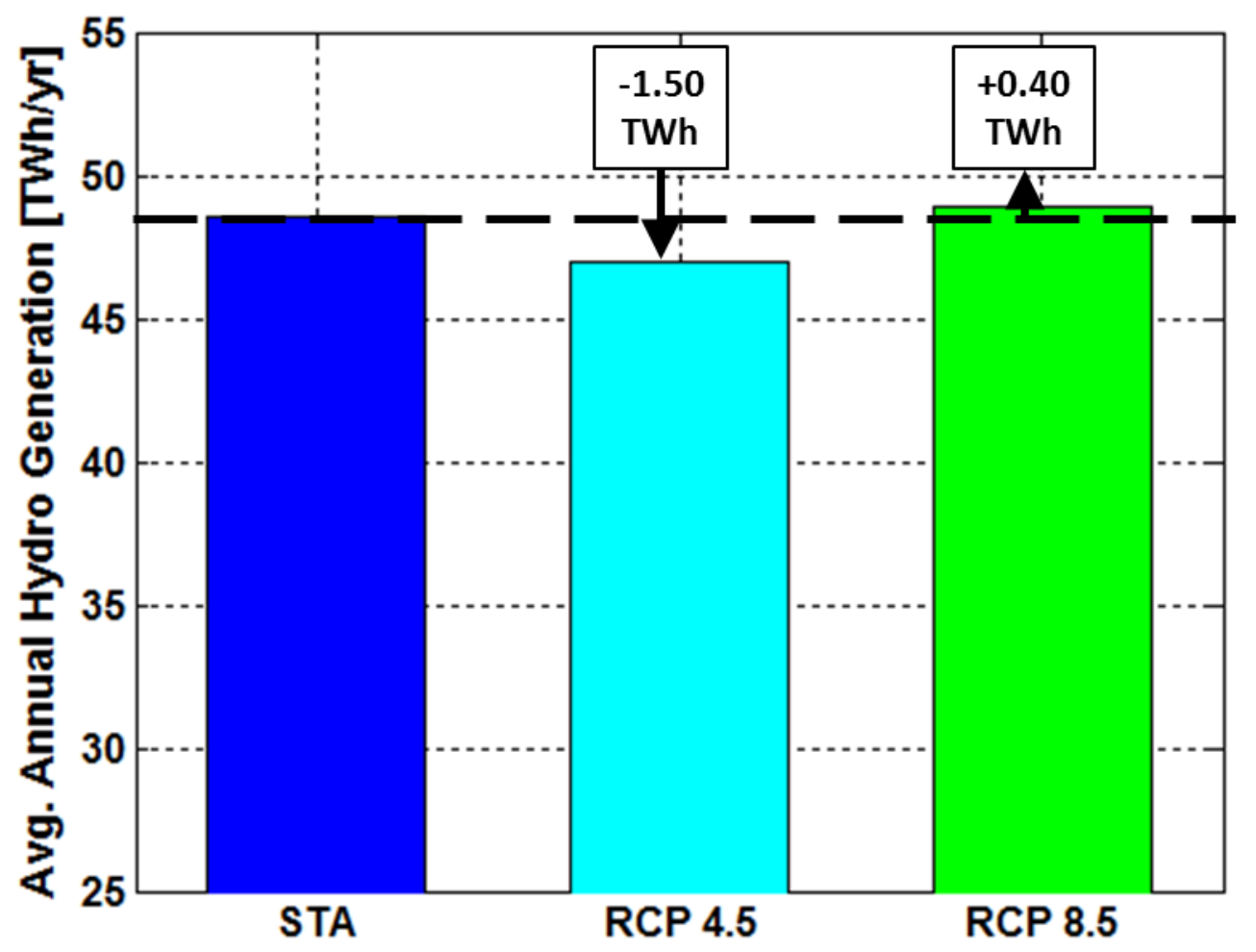

Figure 7 - Average Annual Hydropower Generation: STA vs. RCP 4.5 and RCP 8.5 


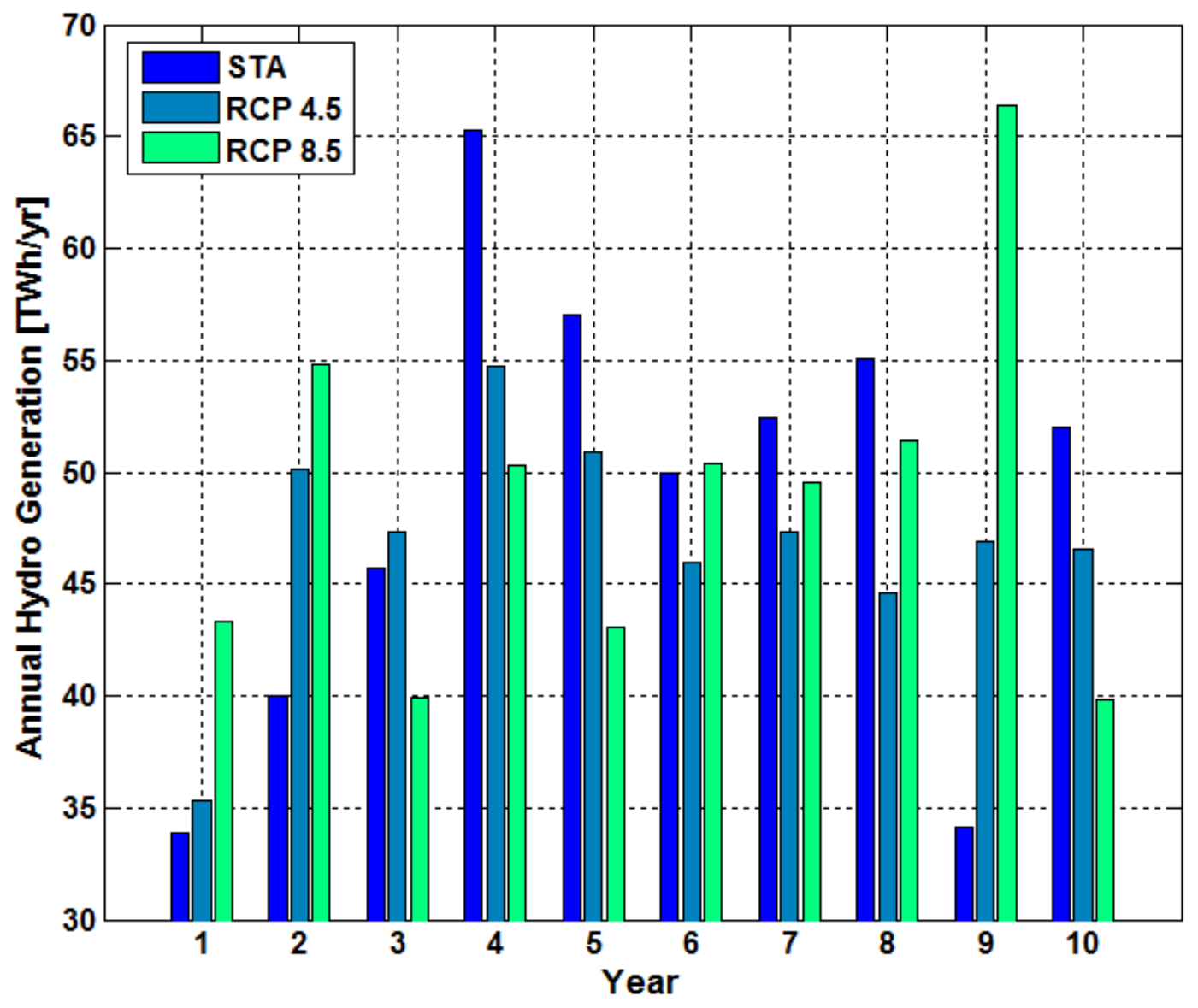

Figure 8 - Annual Hydropower Generation for Each Year 


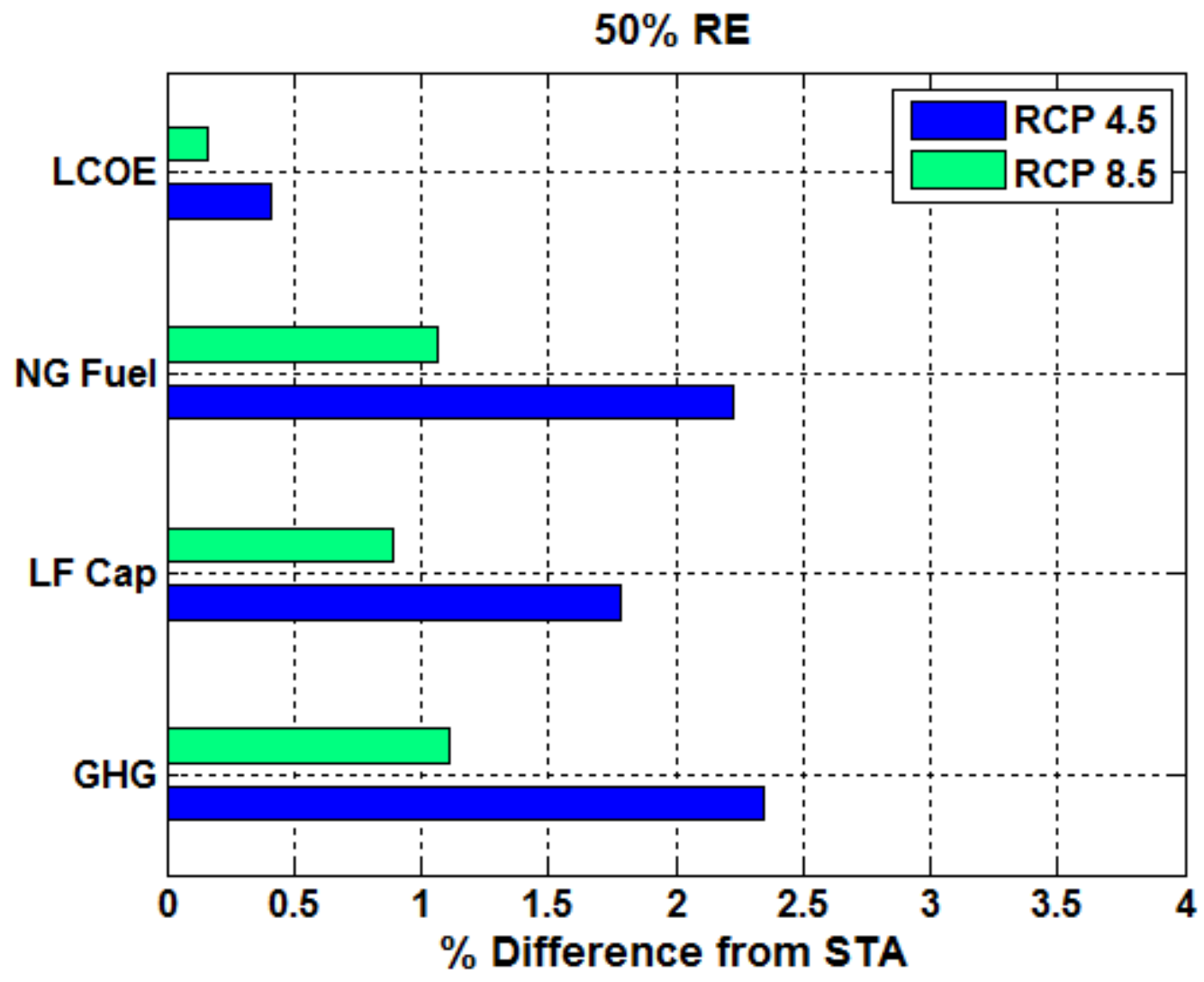

Figure 9 - Percentage Difference in Greenhouse Gas Emissions, Load-Following Capacity, Natural Gas Fuel Use, and the Levelized Cost of Electricity from STA values. 


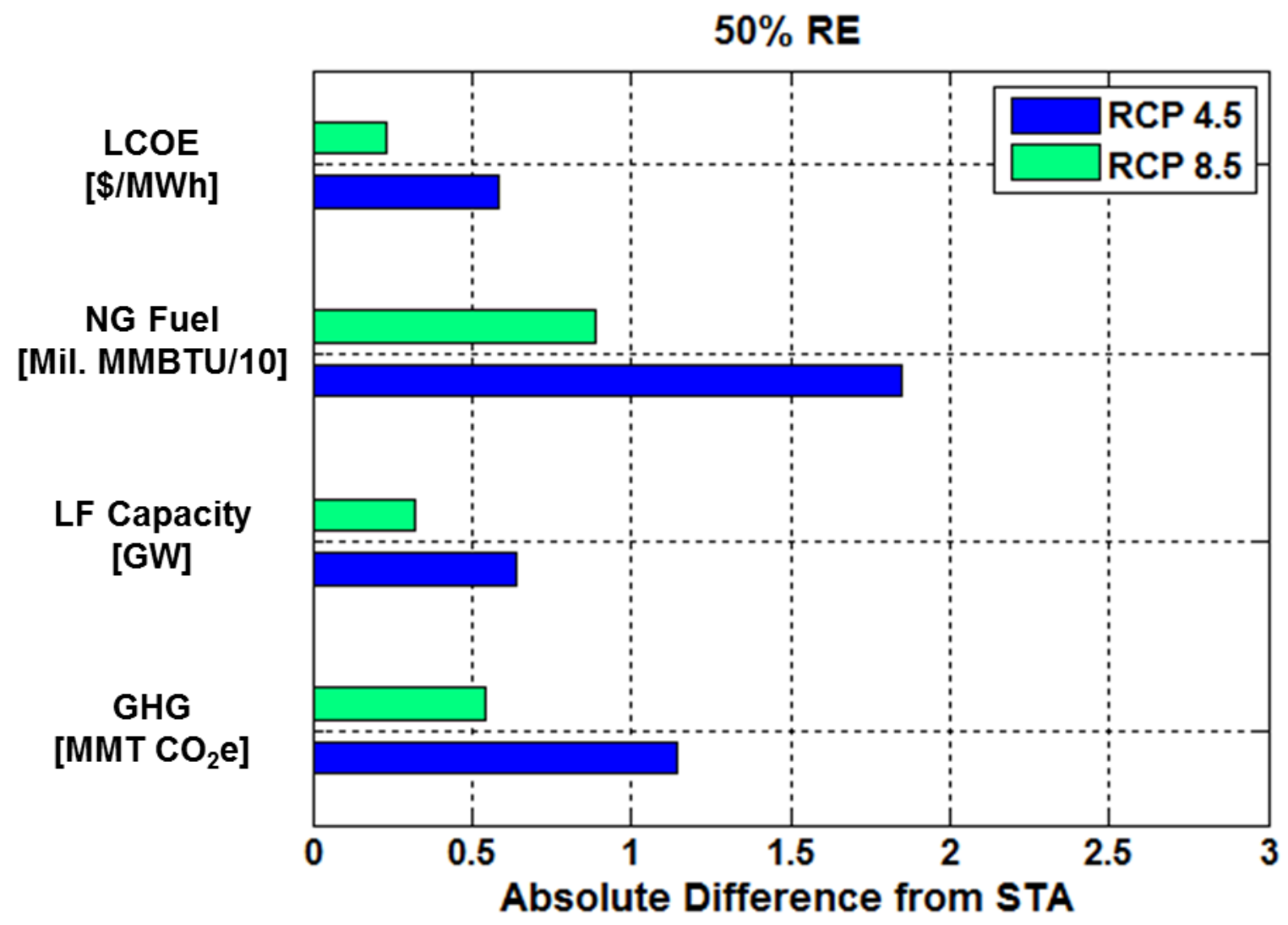

Figure 10 - Absolute Difference in Greenhouse Gas Emissions, Load-Following Capacity, Natural Gas Fuel Use, and the Levelized Cost of Electricity from STA values.

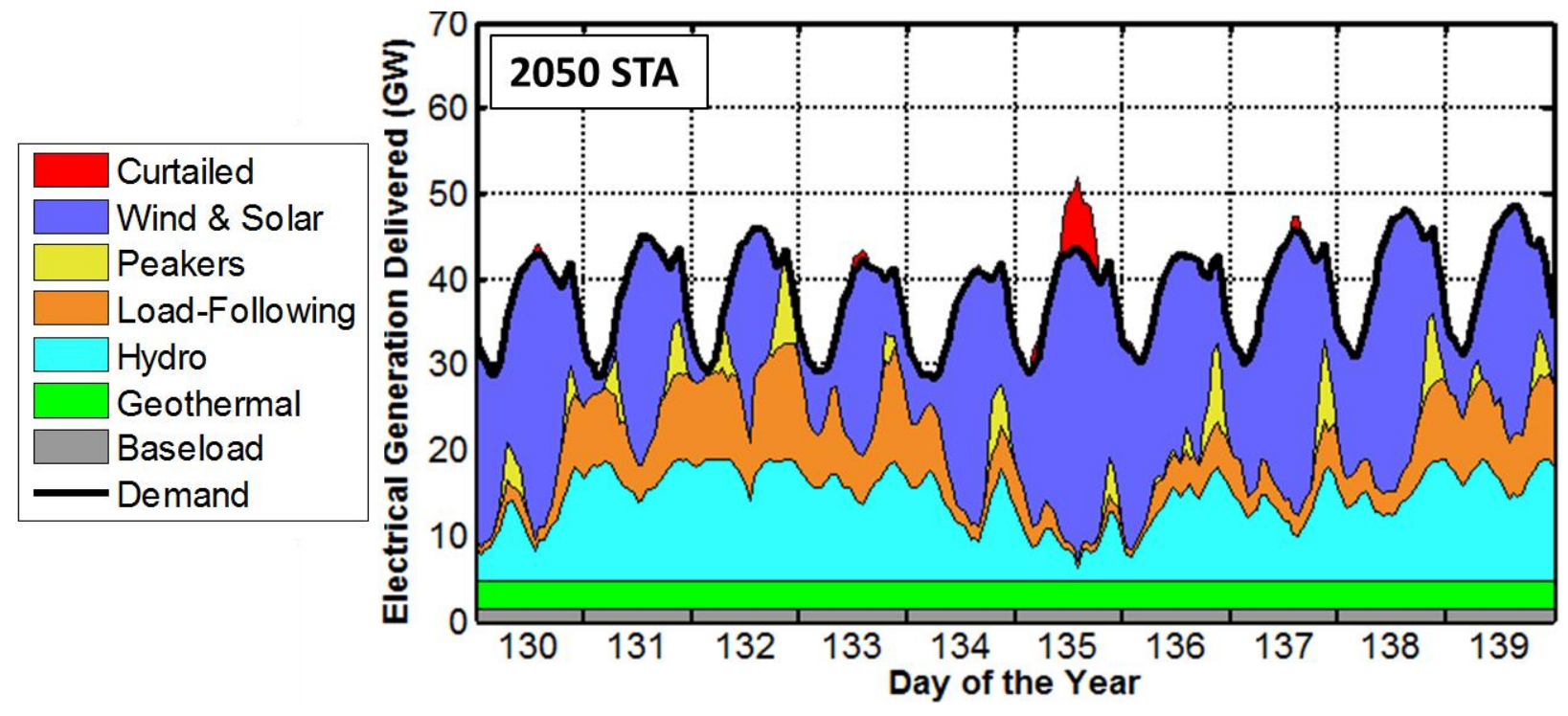

Figure 11 - Snapshot Timeseries - 2050 STA / 50\% RE 


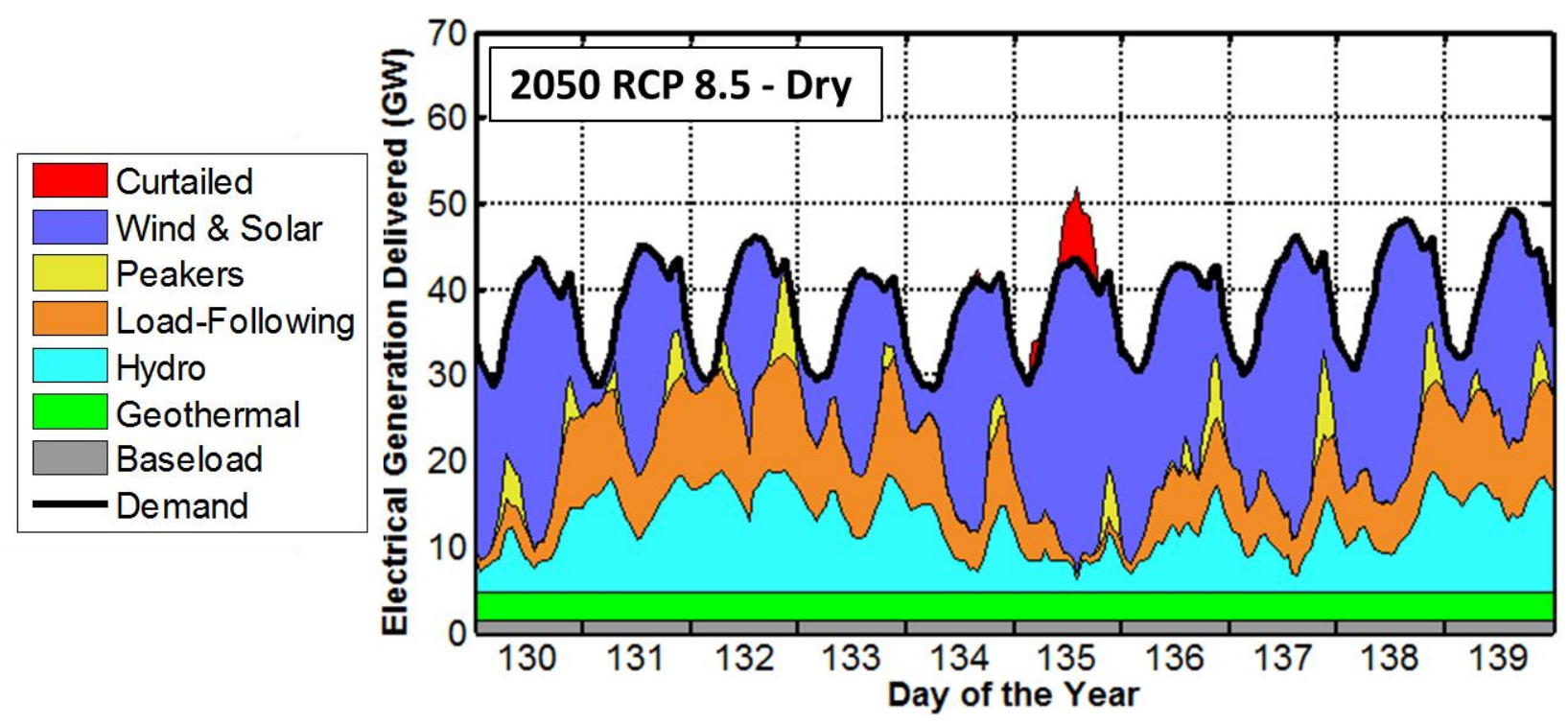

Figure 12 - Snapshot Time series - 2050 RCP 8.5 / 50\% RE / Dry Year

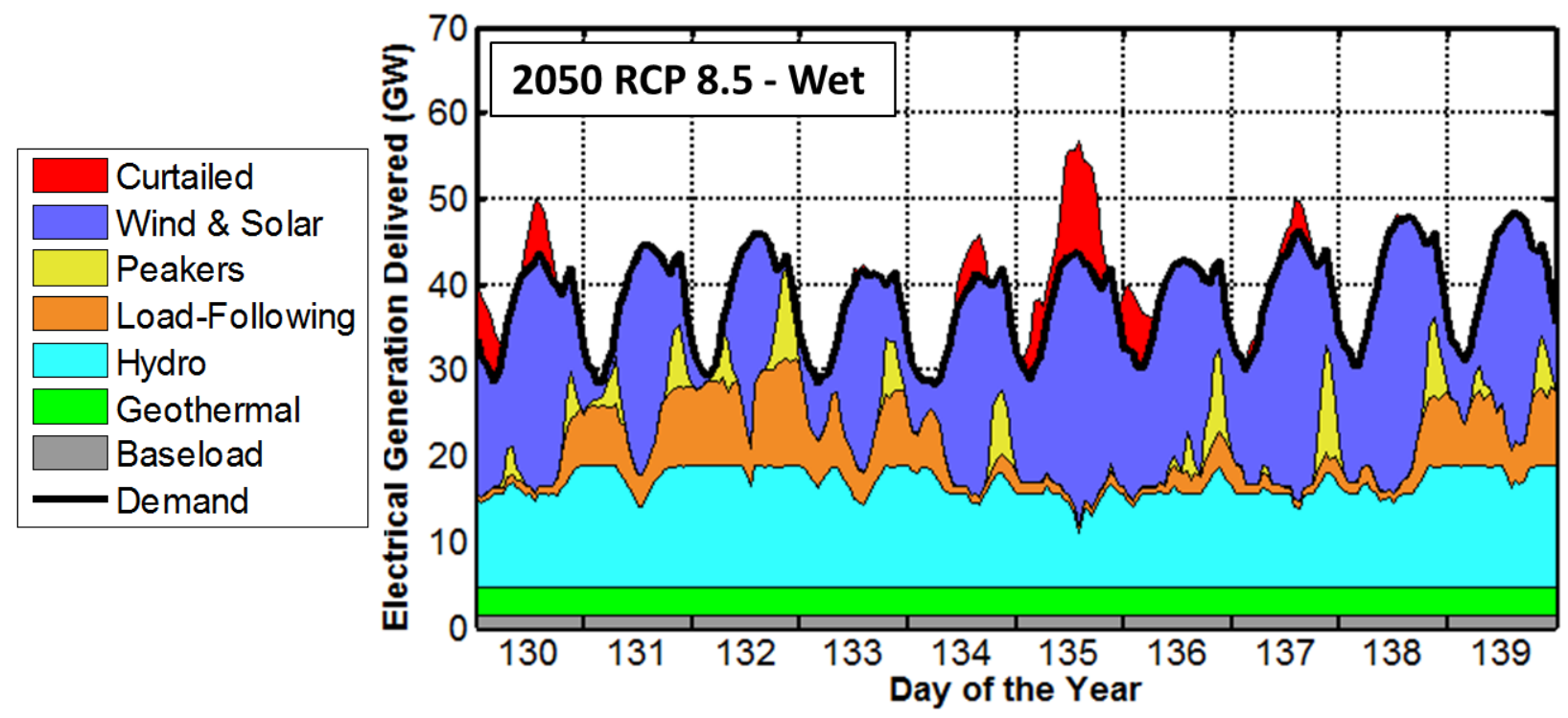

Figure 13 - Snapshot Time series - 2050 RCP 8.5 / 50\% RE / Wet Year 


\section{Tables}

Table 1 - Water Reservoir Characteristics. (*) indicates a pumped hydropower reservoir.

\begin{tabular}{|c|c|c|c|}
\hline Reservoir & Capacity $\left[\mathbf{M m}^{3}\right]$ & $\frac{\text { Minimum Fill Level }}{\left[\mathbf{M m}^{3}\right]}$ & $\begin{array}{c}\text { Hydropower Capacity } \\
{[\mathbf{M W}]}\end{array}$ \\
\hline Don Pedro & 2504.0 & 123.3 & 203 \\
\hline Exchequer & 1264.3 & 141.9 & 94.5 \\
\hline Folsom Lake & 1205.1 & 111.0 & 198.7 \\
\hline Millerton Lake & 641.4 & 148.0 & 300 \\
\hline New Melones & 2985.0 & 98.7 & 819 \\
\hline Lake Oroville & 4364.1 & 36.5 & 165 \\
\hline Pine Flat & 1233.5 & 55.9 & 676 \\
\hline Lake Shasta & 5614.8 & 143.1 & 140 \\
\hline Trinity Lake & 3019.6 & 493.4 & 424 \\
\hline San Luis* & 2515.1 & 9.9 & 2080 (Total) \\
\hline Lake Mead & 39914.2 & 3955.8 & 1148 (CA-Eff) \\
\hline Castaic Lake & 400.9 & & 11 \\
\hline Pyramid Lake* & 209.7 & 362.6 & 1507 \\
\hline
\end{tabular}

Table 2 - Renewable Mix for 50\% Renewable Penetration Level

\begin{tabular}{|c|c|}
\hline Renewable Type & Installed Capacity \\
\hline Geothermal & 5.9 \\
\hline Solar PV & 21.3 \\
\hline Solar Thermal & 21.3 \\
\hline Onshore Wind & 30.2 \\
\hline Small Hydro & 1.6 \\
\hline Biomass & 1.3 \\
\hline
\end{tabular}

